\title{
Conveying More (or Less) Than We Realize: The Role of Impression-Management in Feedback-Seeking
}

\author{
SUSAN J. ASHFORD \\ School of Business Administration, University of Michigan
}

AND

\section{GREGORY B. NORTHCRAFT}

Department of Management and Public Policy, University of Arizona

\begin{abstract}
This paper reports two studies concerning impression management, impression formation, and feedback-seeking. Study 1 demonstrated that people seek less feedback when being observed and respond to situational norms regarding the appropriate frequency of seeking. However, Study 2 showed that when an individual has a superior performance history, seeking enhances observers' impressions of the seeker's personal characteristics and performance potential in the organization. The implications of these findings for feedback-seeking and the provision of feedback in organizations are discussed. (C) 1992 Academic Press, Inc.
\end{abstract}

Feedback research typically exhorts supervisors to provide feedback frequently (cf. Ilgen, Fisher \& Taylor, 1979; Larson, 1984). Indeed, given that feedback can be an invaluable aid in correcting misguided work behaviors (Vroom, 1964; Erez, 1977), it would be desirable if feedback flowed freely in organizations. In actuality, however, the flow of feedback in organizations typically is somewhat constrained. Superiors seldom formally review performance more than once a year and individuals at all levels are reluctant to give feedback informally (Blumberg, 1972; Schoeneman, 1981). These constraints on the flow of feedback might be less costly if employees felt free to seek feedback on their own when they wanted or needed it. However, while the act of seeking may reflect an employee's concern with being an effective performer, Ashford and Cummings (1983) have suggested that employees may not initiate overt feedback-seeking (i.e., directly ask others for feedback using an inquiry strategy) because of the perceived impression-management costs associated

The authors thank Craig Pinder and the Tuck School Research Colloquium (including visiting scholar Georgio Inzerelli) for their comments on an earlier draft of this paper. Address correspondence and reprint requests to Susan J. Ashford, School of Business Administration, University of Michigan, Ann Arbor, MI 48109-1234. 
with feedback search. Organizations are made up of people who observe and make judgments about each other. If people believe that feedbackseeking conveys a negative impression of the seeker-for instance, that the seeker is insecure, uncertain, or incompetent--they will be less likely to seek. This paper presents two studies examining the role of impressionmanagement dynamics in feedback-seeking. Study 1 tests whether perceived impression-management costs influence an individual's decision to seek feedback. Study 2 examines the other side of the impressionmanagement issue: Do observers use an individual's feedback-seeking as a cue in impression formation?

\section{Study 1}

Impression management is a central psychological issue in the performance appraisal process. Supervisors control employees' access to important rewards such as pay raises and promotions. For employees, therefore, their supervisor's impressions of them are critical. Researchers have documented not only the tactics individuals use to gain a higher initial performance evaluation, such as setting higher public goals (Ferris \& Porac, 1984) or providing excuses and apologies for poor performance (Eagly \& Acksen, 1971; Wood \& Mitchell, 1981), and also the tactics undertaken to repair one's image after receiving a negative evaluation (Eagly, 1967; Schneider, 1969). While there are many things employees can do to promote a positive image or repair a temporarily damaged image, there are also behaviors that employees may explicitly want to avoid doing to prevent a negative impression (e.g., asking lots of questions or smoking excessively). Arkin (1981) includes these tactics under the motive: protective self-presentation.

Clearly there are both potential impression-management gains and costs that must be managed in the performance appraisal process. While recent research has emphasized how people can use feedback-seeking for impression-management gains (Wolfe \& Bies, 1989), the current research tests Ashford and Cummings' (1983) hypotheses regarding the impression-management costs of seeking. Impression-management costs are incurred when taking an action (such as seeking feedback) detracts from an individual's desired social image or identity (Tetlock \& Manstead, 1985). Ashford and Cummings (1983) suggested that, other things being equal, individuals will be less likely to seek feedback when others can observe them doing so because seeking feedback exposes their need for this information. This need for feedback could be interpreted as a sign of weakness, uncertainty, or lack of self-confidence. Therefore, in order to maintain a confident self-image, individuals may curb their seeking when an audience is present.

The current study also varied the evaluative intent of the audience. 
Arkin (1981, p. 317) has argued that audience characteristics should affect actors' subjective probabilities of disapproval and subsequent loss, and therefore their impression-management motives. Arkin (1981) notes, though, that there is little empirical evidence to substantiate this claim. The presence of audiences that are explicitly evaluating the subject should increase protective self-presentation motives (and decrease feedback-seeking) relative to audiences without an explicitly evaluative intent. Thus Hypothesis 1 suggests that the evaluative context of seeking will significantly influence the frequency of feedback seeking. Individuals will seek less feedback when their seeking is public than when it is private, and will seek the least feedback when their public seeking is observed by an evaluative (rather than nonevaluative) audience. Thus:

\footnotetext{
$\mathrm{H}_{\mathrm{la}}$ : Individuals will seek less feedback when others can observe their requests for feedback. They will seek even less feedback if observers are acting in an explicitly evaluative capacity.
}

In an initial test of this hypothesis, Northcraft and Ashford (1990) found only marginally significant reductions in feedback-seeking when audiences were present. However, their results could be attributed to the manipulation of public seeking in their study (requiring subjects to turn in a colored card in the company of other performers). This manipulation may not have been sufficiently vivid for subjects to see it as exposing important information about themselves. Further, their task (stock portfolio management) was unfamiliar to subjects and thus may not have elicited impression-management concerns. It may not have mattered to subjects that seeking revealed their uncertainty because the task was unfamiliar and not central to their self-concepts. The current study provided a more appropriate test of this hypothesis. The public seeking manipulation was more vivid and the experimental task tapped characteristics relevant to all subjects-e.g., how well individuals relate to people and individuals' judgments about situations.

Ashford and Cummings (1983) have argued that individuals curtail feedback search when an audience is present because they perceive risks in seeking and feel anxious in light of those risks. Arkin's (1981) notion of protective self-presentation motive is consistent with this argument. While Northcraft and Ashford (1990) also hypothesized an impressionmanagement motive in reduced seeking, they did not examine the intervening psychological states hypothesized by Ashford and Cummings (1983). Rather, Northcraft and Ashford (1990) simply examined the end result-the amount of seeking in private as opposed to public contexts. This study extends Northcraft and Ashford's previous work by directly measuring the intervening psychological states hypothesized to underlie reduced feedback-seeking in public contexts. Thus: 
$\mathrm{H}_{1 \mathrm{~b}}$ : When feedback must be sought in the presence of an audience, decreased feedback-seeking will be accompanied by: (1) more nervousness about seeking feedback and (2) more anxiety about the task.

Norms about the appropriate frequency of feedback-seeking should also affect feedback search. A primary motive for feedback-seeking in organizations is that people are uncertain how to act and want to know what to do. Interestingly, one thing people may be uncertain of is how much feedback to seek. In uncertain situations, individuals frequently rely on social cues to suggest appropriate behavior (Festinger, 1954). In this way, social cues act much in the way that decision anchors do in more quantitative decision situations (e.g., Northcraft \& Neale, 1986)-they serve as reference points that people use as a basis for generating their own behaviors. Norms for appropriate behavior are one form of social cue. If norms suggest that feedback-seeking is typically a frequent event, then regardless of the publicness or evaluativeness of the context individuals should take this into account in deciding whether to seek. Thus:

$\mathrm{H}_{2}$ : Norms suggesting that feedback-seeking is a frequent occurrence should promote subsequent feedback-seeking; norms suggesting that feedback-seeking is an infrequent occurrence should inhibit feedback-sceking.

Norms regarding feedback search also may reduce the perceived impression-management costs of seeking feedback in a public context. Individuals assess impression-management costs by attempting to infer how others may see their behaviors (Schneider, 1981). Individuals may feel that frequent feedback-seeking will not be judged negatively in contexts where it is normatively sanctioned to frequently seek feedback. Attribution theory (Kelley, 1967) suggests that in order to draw inferences regarding another person, observers assess the consistency of behaviors across situations, across time, and across people. Behaviors peculiar to any particular individual will be seen as diagnostic of that individual's character. If frequent feedback-seeking is the norm, then any individual's seeking does not reveal anything distinctive about that individual to others observing the behavior. Therefore, feedback-seekers may feel that the impression-management costs of feedback-seeking are reduced when frequent feedback-seeking is the norm. A frequent feedback-seeking norm should then "release" individuals from the usual impression-management costs of feedback-seeking. This argument suggests the following interaction between norms and audience effects:

$\mathbf{H}_{3}$ : The presence of an audience will inhibit feedback-seeking unless there is a "frequent feedback-seeking" norm.

Finally, while all individuals respond to perceived impressionmanagement costs to some extent, certain individuals are particularly 
sensitive to the presence of an audience. These individuals ought to be particularly responsive to feedback-seeking concerns. An individual difference variable, public self-consciousness, studied primarily in psychology, taps this heightened sensitivity to audiences. Public selfconsciousness involves an awareness of the self as a social object (Fenigstein, 1979, p 76). Publicly self-conscious individuals are susceptible to feelings of being observed when in the presence of others (Argyle \& Williams, 1969; Fenigstein, Scheier \& Buss, 1975), can usually infer how others perceive them, and are highly sensitive to how others react to them in social situations (Fenigstein, 1979).

Their heightened awareness of the self as a social object should make publicly self-conscious individuals more responsive to the demands of their social situations. If Ashford and Cummings (1983) are correct that public feedback-seeking carries impression-management costs, then these individuals should be more aware of these costs than will individuals low in public self-consciousness. This logic suggests that:

$\mathrm{H}_{4}$ : Individuals high in public self-consciousness will reduce feedback-seeking to a greater extent than will individuals low in public self-consciousness when seeking must be done in the presence of an audience.

These hypotheses were tested by examining subjects' performance on an "in-basket" exercise. The study did not attempt to replicate any realworld setting. Rather, the context in which subjects completed this in basket was designed to recreate the psychological experiences thought to be relevant to feedback-seeking and to isolate those variables suggested by Ashford and Cummings (1983) and the preceding hypotheses as primary determinants of feedback-seeking behavior.

\section{Method}

Subjects. Sixty-seven undergraduate psychology students (38 male, 29 female) at a northeastern college participated in partial fulfillment of a course requirement. Subjects were randomly assigned to experimental conditions.

Design overview. Subjects participated in a computerized in-basket task designed by Sandelands and Calder (1987) and adapted for this study. Subjects were instructed to assume the role of manager in the XYZ Corp. Each subject had 30 min to read and respond to 10 office memoranda on a variety of topics. Each memorandum was one or two computer screens in length and formatted to resemble an actual office memorandum. When the subject finished reading a memorandum, the computer presented a set of possible responses to the memorandum (from four to eight responses per memo; $\bar{X}=5$ ) and the subject chose one from among the offered alternatives. Following selection of a response, the subject could go on to 
the next memorandum or request feedback on the appropriateness of the selected response. If a subject requested feedback, the computer displayed a narrative feedback paragraph discussing the implications of each of the possible responses for that memo. This paragraph was the same regardless of which response the subject had chosen. The feedback paragraphs were constructed to be factual and neutral in tone.

Though the task of being a "manager" was unfamiliar to subjects, the component activities of this task-making judgments about people and situations and taking actions that will not alienate people-were thought to be highly relevant to these subjects' self-concepts. Seven of the 10 memos asked for the manager's judgment about employees or about actions that would affect employees; the other three concerned operations decisions. The process of deciding how to deal with the interpersonal situations faced by this fictitious manager is argued to be both more familiar to these subjects and more personally involving than were the stock buy-and-sell decisions made by Northcraft and Ashford's (1989) subjects.

The context in which the in-basket was completed varied across subjects based on a fully crossed 3 by 3 (Seeking Context by Norms) factorial design. The first independent variable was the Seeking Context in which the in-basket exercise was performed. There were three conditions: Public-Evaluative, Public-Nonevaluative, and Private. Under the Public conditions, while completing the in-basket exercise, the subject was seated in front of a desk-top computer in a large classroom. Two "observers" were seated on either side of the subject, about $10 \mathrm{ft}$ away. Under the PublicEvaluative condition, subjects were told that the observers were there to evaluate them-to determine the kind of person they were from observing the way that they went about the task. Under the Public-Nonevaluative condition subjects were told that the observers were explicitly not evaluating them. To make it plausible to subjects that the observer could actually see their work, everything which appeared on the subject's computer screen also appeared on a large rear-projection screen (approximately $10 \mathrm{ft} \times 10 \mathrm{ft}$ ) behind the subject except the contents of any feedback requested by the subject. Requested feedback was printed on a desk-top printer for the subject's access only. The rear-projection screen was clearly visible to the subject and both observers. In the Private condition, the subject was seated in front of a desk-top computer, but in one cubicle of a multiple-cubicle computer lab. No other people were visible to the subject or could view the subject's computer screen. Requested feedback was printed on the subject's computer screen.

The second independent variable was Norms. There were three conditions: High, Low, and No Norms. Norms were manipulated by sharing the alleged end-of-exercise feedback summary from a previous subject 
prior to beginning the current subject's in-basket exercise. Under the High Norm condition, the results summary revealed that the previous subject had requested feedback following 9 of the 10 in-basket items. Further, the subject was described by the experimenter as "pretty typical," and the results summary noted that the mean number of feedback requests by subjects to date was 8.8 . In the Low Norm condition, the "typical subject" had requested feedback only once. This rate was also described as pretty typical, and the mean number of requests by subjects to date was noted to be 1.2. In the No Norm condition, the results summary contained no information about the previous subject's feedback requests.

Subject's self-consciousness was assessed using the Fenigstein et al., (1975) scale. This scale has been shown to have adequate reliability in several previous studies (cf. Fenigstein, 1979; Turner, Carver, Scheier, \& Ickes, 1978). Alpha for this study was .80 .

Procedure. Subjects reported to a large classroom in order to participate. Upon arrival, all subjects completed a "managerial readiness" pretest questionnaire which contained the Public Self-consciousness Scale. Upon completion of the questionnaire, the in-basket exercise and the justification for the study were presented to the subject. It was explained that the researchers-both business school professors-often are called upon to counsel MBAs on their management skills. The in-basket was described as a computerized exercise designed to assist the professors in assessing students' management skills. The subjects were told that the in-basket had been tried out with some practicing managers but not yet with students.

It was further explained that the in-basket provided several management-potential evaluation opportunities. Under both Public Seeking Context conditions, subjects were told that two observers would be observing their behaviors. Under the Public-Evaluative condition, subjects were told that the observers would be attempting to discover the kind of person they were from observing the way that they went about the task. Subjects were shown a short questionnaire that observers would complete assessing several personal characteristics (such as self-confidence). Under the Public-Nonevaluative conditions, subjects were told that one observer was there to learn how to run the study and the other observer was there in case any technical (computer) problems occurred. In both Public conditions, it was pointed out that the observers also would see (via the overhead screen) everything that appeared on the subject's computer but would not see any feedback messages solicited.

Under all conditions, it was noted that the in-basket program could provide two forms of feedback to subjects: overall feedback (provided at the end of the exercise) and feedback about the appropriateness of re- 
sponses to any of the 10 memos (provided by request only after each memo). The "previous subject's overall feedback" (which comprised the Norms manipulation) was used to demonstrate the end-of-exercise feedback. The end-of-exercise feedback consisted of two parts: (1) the Norm manipulation, i.e., a summary of the previous subject's feedback requests, and (2) some apparently evaluative information relating to the previous subject's selected responses to the memos (e.g., "decision style = B3"). The apparently evaluative information gave no clues as to appropriate ways to tackle the task and was the same for all subjects. The subject was then led through a practice memo on the computer to show how the exercise worked and to demonstrate feedback available after each memo. The practice memo revealed that feedback, if requested, provided comments about the advantages and implications of each possible forced-choice response to the memo. Subjects were informed that this after-memo feedback was based on the previous responses of a sample of practicing managers and the expert knowledge of the two researchers.

After demonstrating the practice memo, the researcher told the subject to begin the exercise. Subjects went through the practice memo to practice using the computer before starting the exercise. Subjects were told they had $30 \mathrm{~min}$ to complete all 10 memos.

Following the completion of the tenth memo, each subject was asked to complete a short follow-up questionnaire. The questionnaire requested information about the task (e.g., "How difficult was the task?") and about the subject (e.g., "How anxious were you during the task?," "During the experiment, did you feel nervous about asking for feedback?"'). These follow-up questions provided single-item measures of the dependent and intervening variables, as well as the manipulation checks for the study. The computer also recorded the number of requests for feedback following the individual memos made by each subject. Following completion of the follow-up questionnaire, subjects were debriefed and thanked for their participation.

\section{Results}

Manipulation checks. The manipulation checks confirmed the effectiveness of the experimental manipulations. First, $100 \%$ of subjects under the two Public Seeking Context conditions reported that they were being watched as they performed the task, versus $15 \%$ of subjects in the Private Seeking Context condition $\left(\chi^{2}=50.77, p<0.01\right)$. Additionally, subjects under the Public-Evaluative Seeking Context condition were significantly more likely than subjects under the Public-Nonevaluative Seeking Context condition ( 84 versus $46 \%$ of subjects) to report that the observers 
were evaluating their performance rather than the task $\left(\chi^{2}=6.26, p<\right.$ $.05)$.

Second, subjects under the Low, High, and No Norm conditions reported appropriate beliefs about how often other subjects typically seek feedback in this task (means of $2.29,8.00$, and 5.56, respectively; all intercell $t \mathrm{~s}>4.22, p \mathrm{~s}<.01$ ) and how often they thought a friend doing this task "should" seek feedback about his/her performance (means of $3.33,7.70$, and 5.36, respectively; all intercell $t \mathrm{~s}>2.98, p \mathrm{~s}<.01$ ). It is interesting to note that there was also a significant main effect for Seeking Context on both of these variables. Subjects' beliefs about how frequently other subjects typically seek feedback were the lowest under the PublicEvaluative Seeking Context condition, second under the PublicNonevaluative condition, and highest under the Private condition (means of $4.85,5.07$, and 6.15 , respectively $F(1,49)=5.20, p<.05$ ). Beliefs about how often a friend should seek feedback also demonstrated this pattern (means of $4.80,5.13$, and 6.46 , respectively, $F(1,48)=6.06, p<$ $.05)$. These findings provide additional support for the impact of the seeking context manipulation.

The experimental groups did not significantly differ in their ratings of the usefulness of feedback they received $(p>.82)$. The mean number of feedback requests for the total sample was 5.5 times out of 10 opportunities.

Experimental hypotheses. The mean number of feedback requests by subjects (up to 10 requests possible) are displayed by Seeking Context and Norm conditions in Table 1 . Table 2 presents results of an analysis of variance performed to test the experimental hypotheses using specific planned comparisons among treatment means. (For an explanation of this technique, see Winer, 1971, p 175.)

A planned comparison capturing the expected relative levels of feedback requests across Seeking Context conditions proposed in Hypothesis 1a was supported. Subjects sought less feedback in Public (4.30 requests) than in Private (6.5 requests) Seeking Contexts, and less feedback in

TABLE 1

Mean Requests for Feedback-Seeking Context Condition

\begin{tabular}{|c|c|c|c|c|c|c|c|}
\hline \multirow{2}{*}{$\begin{array}{c}\text { Norm } \\
\text { condition }\end{array}$} & \multicolumn{2}{|c|}{ Private } & \multicolumn{2}{|c|}{$\begin{array}{c}\text { Public } \\
\text { nonevaluative }\end{array}$} & \multicolumn{2}{|c|}{$\begin{array}{c}\text { Public } \\
\text { evaluative }\end{array}$} & \multirow{2}{*}{$\begin{array}{l}\text { Row } \\
\text { mean }\end{array}$} \\
\hline & Mean & SD & Mean & SD & Mean & SD & \\
\hline Lo & 3.75 & 1.67 & 2.80 & .84 & 1.50 & 1.41 & 2.67 \\
\hline High & 7.88 & 2.23 & 6.40 & 3.13 & 5.51 & 2.12 & 6.53 \\
\hline No & 7.60 & 2.41 & 5.20 & 3.83 & 3.95 & 3.13 & 5.81 \\
\hline Column mean & 6.50 & & 4.80 & & 3.80 & & \\
\hline
\end{tabular}


TABLE 2

ANALYSIS OF VARIANCE RESULTS-STUDY 1

\begin{tabular}{lrrrrrr}
\hline \multicolumn{1}{c}{ Source } & \multicolumn{1}{c}{ SS } & \multicolumn{1}{c}{ DF } & \multicolumn{1}{c}{ MS } & \multicolumn{1}{c}{$F$} & $p$ & $R^{2}$ \\
\hline Total & 620.28 & 66 & 9.38 & & & \\
Explained & 340.30 & 17 & 20.02 & 3.50 & .000 & \\
H1-seeking context & 81.37 & 1 & 81.37 & 14.24 & .01 & 0.13 \\
H2-norms & 163.88 & 1 & 163.88 & 28.68 & .001 & 0.26 \\
H3-norms $\times$ seeking context & 2.97 & 1 & 2.97 & 0.52 & ns & \\
H4-public self-consciousness & & & & & & \\
$\quad \quad \quad$ seeking context & 9.82 & 1 & 9.82 & 1.72 & $\mathrm{~ns}$ & \\
Residual explained & 82.26 & 13 & 6.32 & 1.11 & $\mathrm{~ns}$ & \\
Error & 279.98 & 49 & 5.71 & & & \\
\hline
\end{tabular}

Public-Evaluative (3.8 requests) than in Public-Nonevaluative (4.8 requests) Seeking Contexts $(F(1,49)=14.24, \mathrm{p}<.01)$.

Hypothesis 2 suggested that norms should affect feedback-seeking frequency. A planned comparison capturing the expected levels of feedback requests for the different norm conditions suggested by Hypothesis 2 was supported. Subjects under the Low Norm condition sought less feedback (2.67 requests), and subjects under the High Norm condition sought more feedback (6.53 requests) than did subjects in the No Norm condition (5.81 requests; $F(1,49)=28.68, \mathrm{p}<.001)$.

Hypothesis $1 \mathrm{~b}$ proposed that Seeking Context would influence subjects' psychological states and that these psychological states in turn would affect feedback seeking. Consistent with this hypothesis, a planned comparison for Seeking Context was significant for the dependent measure "nervous about seeking feedback" $(F(1,43)=25.43, p<.001)$. Subjects reported being more nervous about seeking in Public than in Private seeking contexts, and more nervous about seeking in PublicEvaluative than in Public-Nonevaluative contexts. Subjects did not differ by Seeking Context in "anxiety about the task" ( $F<2.0$, ns). A parallel analysis revealed that subjects did not differ significantly by Norm condition in either nervousness or anxiety $\left(F_{\mathrm{S}}<2.0, \mathrm{~ns}\right)$.

Regression analysis was used to test whether these psychological states in fact mediated the effects of Seeking Context and Norms on feedbackseeking. The results of this analysis are shown in Table 3. First, (a) frequency of subjects' feedback requests was regressed on Seeking Context and Norms. This provided support for the significant influence of Seeking Context and Norms noted in the tests of Hypotheses 1a and 2. Next, (b) frequency of subjects' feedback requests was regressed on nervousness about seeking feedback and anxiety about the task only. Nervousness was significantly negatively related to subjects' feedback requests $(F=14.27, p<.001)$; anxiety was marginally positively related to 
TABLE 3

Test of Mediating EfFects of Nervousness and AnXIETy on FEedBaCk-SEeking Frequency

\begin{tabular}{lrrr}
\hline & Beta & \multicolumn{1}{c}{$F$} & $p$ \\
\hline a Seeking context & -.248 & 5.109 & .027 \\
Norms & .398 & 13.161 & .000 \\
Adjusted $R^{2}=.204$ & & & \\
b "Nervous about seeking" & -.436 & 14.276 & .003 \\
"Anxious about the task" & .195 & 2.871 & .095 \\
Adjusted $R^{2}=.164$ & & & .008 \\
c "Nervous about seeking" & -.316 & 7.573 & .052 \\
"Anxious about the task" & .211 & 3.935 & .144 \\
Seeking context & -.165 & 2.191 & .001 \\
Norms & .357 & 11.495 & \\
Adjusted $R^{2}=.291$ & & & \\
\hline
\end{tabular}

subjects' feedback requests $(F=2.87, p<.10)$. Finally, (c) frequency of subjects' feedback requests was regressed on Seeking Context and Norms, with Nervousness and Anxiety already in the regression equation. With Nervousness and Anxiety in the equation, Seeking Context no longer was significantly related to subjects' feedback requests $(F=2.19$, $p=.14)$; Norms remained significantly related to subjects' feedback requests $(F=11.49, p<.002)$. These results support the contention that psychological states (at least, nervousness about seeking feedback) mediate the significant effect of Seeking Context on frequency of feedback seeking. The effects of norms, on the other hand, are not significantly mediated by nervousness or anxiety. The norms finding is consistent with Hypothesis 2.

Hypothesis 3 was not supported. The anticipated interaction between Seeking Context and Norms as tested by a third planned contrast was not significant $(F<2.0$, ns). It appears that a frequent-seeking norm did not "release" subjects from the impression-management demands of a Public Seeking Context. Hypothesis 4 also was not supported. A moderated regression was performed to test the effect of the interaction of Public Self-consciousness and Seeking Context on seeking frequency over and above their main effects. The interaction did not significantly contribute to the prediction of feedback seeking frequency $\left(\Delta R^{2}=.01, p>.10\right)$. It appears that high Public Self-consciousness subjects did not curtail their seeking to a greater extent in Public Seeking Contexts than did subjects low in Public Self-consciousness.

\section{Discussion}

The results of Study 1 suggest that people do consider impression- 
management concerns when deciding whether to seek feedback. A seeking context that includes an audience, particularly an audience that a performer believes is attempting to discover the kind of person he or she is, creates nervousness about seeking feedback and significantly deters actual feedback-seeking. This finding corroborates Northcraft and Ashford's (1990) previous findings and suggests a variable-the evaluativeness of the seeking context-that may moderate the strength of impression-management motives. In Northcraft and Ashford's (1990) study, the seeking context consisted of coperformers (other subjects), while the audience in the current study consisted of observers attempting to discern the underlying character of the performer. The observers in this study were both more clearly focused on the performer and more explicitly evaluative than were Northcraft and Ashford's (1990) coperformers, which could account for differences in manifested impressionmanagement concerns.

The findings regarding task anxiety as a mediating variable help rule out one possible alternative explanation for these findings. Specifically, the presence and evaluativeness of the audience did not affect general task anxiety which, in turn, was not significantly related to feedback-seeking. These findings make it more difficult to argue that individuals did not seek simply to get a stressful task over with more quickly. Individuals both did not feel more anxious about the task when performed in front of an audience (evaluative or not) and any anxiety felt did not deter seeking. In fact, experienced task anxiety was marginally positively related to seeking frequency.

The results of this study also suggest that individuals use norms about typical feedback-seeking behavior as situational cues in making decisions about how frequently to seek. Subjects under the Low Norm condition sought significantly less feedback than did those under the No Norm condition, who in turn, sought less feedback than those under the High Norm condition. This finding complements DeWhirst's (1971) field study results indicating that norms regarding the appropriateness of seeking information in general regulated actual information-seeking behavior.

These two findings-audience and norm effects-have important implications for managers hoping to open up the feedback flow in organizations. First, the inhibiting effect of an audience (particularly an explicitly evaluative one) suggests that feedback-seeking will be more constrained in organizations where assessments of an employee's general character are informally collected from a variety of sources (e.g., peers and subordinates) and incorporated into formal performance appraisals. In such situations, peers and subordinates become an evaluative audience, and their presence is, therefore, likely to constrain performers' feedbackseeking efforts. The findings also suggest that anything managers can do 
to reduce the apparent evaluativeness of the context by institutionalizing opportunities for less public feedback exchanges should promote feedback-seeking. The findings regarding the role of norms suggest that managers can promote feedback-seeking by instituting and communicating norms suggesting that most employees generally seek, for instance by encouraging subordinate opinion leaders to model feedback seeking. Such a strategy might be effective during initial socialization and training or in periods where employees' needs for feedback are heightened such as during organizational transitions or downsizings.

The findings also suggest that while norms provide important cues about appropriate levels of feedback-seeking, simply knowing that most people seek frequently will not "release" subjects from the perceived impression-management costs of public inquiry. Contrary to Hypothesis 3 , the impression-management costs of public seeking are quite strong. Even if "everyone is doing it," individuals act as if feedback-seeking may reflect poorly on them individually. Thus, while norms regarding seeking had an important cueing effect (and therefore column means in Table 1 differed), these cues did not eliminate audience effects or significantly reduce nervousness about seeking feedback or anxiousness about the task. Further, under the High Norm-Public-Evaluative condition, subjects sought less feedback than under the High Norm-Private or High Norm-Public-Nonevaluative conditions. These results suggest that (in contrast to Hypothesis 3), even under the High Norm conditions subjects are still responding to seeking context conditions that raise impressionmanagement concerns. Thus, while norms regarding seeking are important, they do not eliminate impression-management concerns. Managers may need to recognize employees' reluctance to seek feedback and provide more extensive feedback in order to get this information to employees.

Finally, this study found no evidence that publicly self-conscious individuals are more reactive to the apparent impression-management costs of public feedback-seeking. The public context in this study may have been strong enough to minimize the impact of individual-difference effects.

In sum, this study found some support for the psychological dynamics hypothesized by Ashford and Cummings (1983). Future research needs to test some of the organizational context variables that might interact with these processes. For example, it may be that a strong, performancecontingent reward structure will override individual's fears about the impression-management costs associated with feedback-seeking. In such situations the payoff from seeking feedback may be so high that most people will seek. Interestingly, our findings suggest that this behavior would become self-reinforcing through time-as more people seek, a 
norm is created sanctioning high seeding, making subsequent seeking less costly.

\section{Study 2}

Study 1 demonstrated that people act as if seeking feedback in public has impression-management costs, as Ashford and Cummings (1983) proposed. However, Schneider (1981) has argued that in order to generate actions that effectively manage impressions and reduce impressionmanagement costs, individuals must be able to infer how others will see their behavior. Thus, "the skilled impression manager must not only be a skilled actor but she [sic] must have some sophisticated knowledge of how various behaviors are likely to be interpreted by the average perceiver and how a particular target will do the job" (Schneider, 1981, p. 29). It is not clear that individuals can capably draw such inferences. The results of Study 1 demonstrate that actors believe that feedback-seeking has impression-management costs. This implies that, in turn, observers' impressions of people should be intluenced by whether those people do or do not seek feedback. Study 2 tests this general proposition along with three hypotheses derived from an attribution theory framework regarding the relative impression-management costs of feedback-seeking for various types of individuals. In effect, Study 2 addresses the question: If actors feel that their feedback-seeking will be interpreted negatively, do they in turn negatively interpret feedback-seeking by others? From a practical standpoint, if individuals are inaccurately assessing the impression-management costs of seeking feedback, then they could be needlessly reducing the amount of this valuable information that they seek.

As Schneider (1981, p. 32) points out, we know next to nothing about the way a given bit of behavior (e.g., a feedback-seeking attempt) gets interpreted. For clues, though, observers are thought to take into account discounting cues (Kelley, 1973) in determining the extent to which an action (e.g., feedback-seeking) signifies something about the individual engaging in it. Discounting cues reduce the diagnostic value of a behavior (Kelley, 1973). Study 1, for instance, hypothesized that actors believe that a "frequent-seeking" norm would act as a discounting cue for observers-that it would reduce the extent to which observers will infer anything about a seeker's insecurity from his or her feedback-seeking. Given Ashford and Cummings' (1983) proposal that seeking carries impression-management costs, any operative discounting cue should reduce these costs.

Study 2 examines the effect of three potential discounting cues on observers' impressions of feedback-seekers: the seeker's tenure, role, and performance history. Specifically, new employees may be exempt from the need to maintain a totally self-assured image. Even if feedback- 
seeking exposes uncertainty, the diagnostic value of that uncertainty for inferring anything about a new employee will be discounted by those observing the seeking attempt because most new people are expected to be uncertain. Consistent with this proposition, both Ashford (1986) and Feldman and Brett (1983) found that new employees sought more information and feedback than did those with longer tenure. Thus observers should be more likely to infer an underlying insecurity from frequent feedback-seeking when the feedback seeker is a more senior employee than when he or she is new. This logic suggests:

$\mathrm{H}_{1}$ : Senior employees will be perceived less favorably for seeking feedback than will those with less organizational tenure.

In order to understand and predict the world around them, individuals also are thought to develop prototypes or images regarding the behaviors of individuals occupying certain roles (Staw, 1975). Thus, supervisors expect their subordinates to act deferential, their peers collegial, and their superiors leader-like. Observed actions that are inconsistent with these role prototypes are thought to be particularly distinctive and, therefore, especially diagnostic of the role incumbent's true nature (Jones, Davis, \& Gergen, 1961; Katz \& Bernstein, 1975). Thus if a subordinate is particularly undeferential, this would be seen to be particularly diagnostic of that subordinate's underlying character. If feedback-seeking is (as seekers seem to fear) a sign of weakness, then such seeking is more consistent with some roles than others. For roles in which admitting weakness and uncertainty is inconsistent, feedback-seeking becomes more diagnostic of the role incumbent and, therefore, the impression-management costs of feedback search increase. Since leaders need to portray a strong, confident image (Staw \& Ross, 1987), feedback-seeking seems most inconsistent with the supervisor role. Any seeking on the part of a leader or supervisor would be seen as diagnostic of that supervisor's underlying character. Observers might draw negative inferences regarding the supervisor in this case. When subordinates seek, however, the situation is reversed. Asking for information and soliciting help is congruent with the role of subordinate. Therefore, a particular subordinate's seeking is not likely to be seen as diagnostic of that subordinate's underlying character. Thus while supervisors can exact more costs (e.g., withhold rewards) should they draw a negative impression of a seeker, given that seeking is congruent with the subordinate role, they are less likely to make such an inference. Asking a peer of co-worker for feedback would seem to fall somewhere in between-more role-congruent than asking a subordinate, but not quite as role-congruent as asking a superior. Therefore, the status of the seeker relative to the person from whom the feedback is sought will 
also influence the impression-management costs paid by the seeker. Thus:

$\mathrm{H}_{2}$ : Individuals will be perceived less favorably when seeking feedback from their subordinates than from their co-workers and less favorably when seeking feedback from their co-workers than their supervisors.

Finally, in ascribing characteristics to individuals, observers often attend to a few salient cues and then interpret subsequent information in a manner consistent with those cues (Staw, 1975). For organizational actors, one salient cue is past performance. For example, when told how a group performed, observers interpret information about the group's process and leadership in a way consistent with the performance outcome (Staw, 1975). Thus, high performing groups are perceived to have a more effective group process. This bias also may affect impressions of feedback-seekers. Individuals who are known as superior performers may suffer less impression-management costs for seeking feedback than will seekers who are known as only average performers. Observers may use their knowledge of the seeker's performance reputation to differentially interpret the seeking act due to the bias mentioned above. For superior performers, seeking may be seen as a sign of self-confident openness, while for only average performers that same act might be interpreted as a sign of insecurity. In effect, knowledge of past performance should bias interpretation of the seeking act. As a result, seeking is less costly for superior performers. Thus,

$\mathrm{H}_{3}$ : Individuals with a history of superior performance will be perceived more favorably than will individuals with a history of only average performance.

\section{Method}

Subjects. Subjects were recruited via a mass mailing to the managers in a small northeastern college. The mailing was restricted to nonacademic staff, all with some supervisory responsibilities. Altogether 480 mailings were sent and 312 were returned, for a total response rate of $65 \%$. The sample was $54.7 \%$ female. The mean age of the sample was 39.6 years and the subjects had a mean of 15.6 years of full-time work experience and 5.9 years on their current jobs.

Experimental materials. The mailing consisted of a cover sheet, a oneparagraph vignette, and two pages of questions. The cover sheet described the study as being about perceptions of workers and impression formation in organizations. Subjects returning completed questionnaires were offered the opportunity to win (via a random drawing) one of two $\$ 50$ gift certificates to the restaurant of their choice. Questionnaires were completed anonymously; a separate card was enclosed for the prize drawing. Completed questionnaires were returned via campus mail. 
The data collection methodology followed closely that used by Fedor, Eder, and Buckley (1989). Subjects were presented with a very brief vignette and asked to imagine that the situation described was actually occurring in their own work setting. The vignette asked the subject to assume the role of a manager in a large northeastern organization and assume that he or she is approached by another worker (Bob) concerning a meeting both were involved in the day before in which Bob had made a presentation. The vignettes were varied across subjects on four dimensions: the seeker's (Bob's) role, job tenure, performance history, and purpose (e.g., to seek feedback or seek information). These dimensions provided the independent variables for the study.

"Role" referred to Bob's position in the organization. Bob was described as the subject's subordinate, co-worker, or immediate supervisor. "Job tenure" referred to Bob's tenure in the company. Bob was described as being new to the company, or having been in the company for several years. "Performance history" referred to Bob's past performance in the company, which was either "superior" or "only average." Finally, "purpose" referred to Bob's reason for approaching the manager. There were two conditions: Bob was either requesting feedback on his performance in the previous day's meeting or asking for a copy of an article concerning his project. Thus, the overall design for this study was a fully crossed 3 (role: superior, co-worker, subordinate) by 2 (tenure: new or veteran) by 2 (performance: superior or only average) by 2 (purpose: feedback or article request) factorial design.

The follow-up questions assessed the subject's reactions to Bob. First, subjects were asked to rate the ease with which they could imagine the scene described in the vignette occurring in their own work setting. Fedor et al. (1989) argued that this measure ought to be included in all research studies using scenarios. It is important to determine if respondents view the situation as plausible, akin to something that could occur in their work setting. Second, subjects were asked to rate Bob on five personal characteristics: likability, conscientiousness, proactivity/reactivity, confidence, and insecurity. These items were included to represent both possible positive and negative interpretations of the seeking act. Finally, subjects were asked for their assessments of Bob's ability to perform in his current job and of his advancement potential.

\section{Results}

The focus of Study 2 was the effect of feedback-seeking on observer impression-formation. Therefore, only the effects of feedback-seeking alone or in interactions with the other three independent variables (job tenure, performance history, and role) are relevant to the experimental hypotheses. A MANOVA was performed assessing the effects of the four 
independent variables alone and in combination across the dependent measures. Two dependent measures were computed from subjects' responses to the dependent measures. First, four personal characteristic items were highly intercorrelated (mean $r=.63$ ) and were combined to form a Personal Characteristic measure (alpha $=0.87$ ). One of the five personal characteristics items (conscientiousness) was not highly correlated with the other personal characteristic items and was dropped from the analysis. Second, the performance-potential and advancementpotential items were combined to form a Performance Potential measure (alpha $=.83$ ).

Subjects found the vignettes easy to imagine. The mean ease-ofimaging rating was 4.0 on a five-point scale. Subjects' ease of imagining the situation described in the vignette proved to be significantly or marginally significantly related to several of the independent variables (e.g., seek $\times$ performance, $F=3.14, p<.10$; seek $\times$ role, $F=3.44, p<.05$; role $\times$ tenure, $F=6.8, p<.01$; and performance $\times$ role $\times$ tenure, $F=$ $2.5, p<.10$ ). 'Therefore, following Fedor et al. (1989), ease of imagining the situation described in the vignette was entered into each MANOVA as a covariate. The MANOVA results are presented in Table 4.

Feedback-seeking, performance history, and job tenure all demonstrated significant multivariate main effects across the two dependent measures (multivariate $F \mathrm{~s}$ of $5.13,151.48$, and 6.81 , respectively; $p \mathrm{~s}<$ .01). Performance history demonstrated the strongest multivariate effect, with significant univariate main effects on both dependent measures $(F \mathrm{~s}$ $>144.37, p s<.001)$; those with a history of superior performance were perceived more favorably than were those with an only average performance history. Feedback-seeking demonstrated significant univariate main effects on the Performance Potential measure only $(F=10.29, p<$ .01 ) feedback-seekers were perceived more favorably than those who didn't seek feedback. (However, note the significant interaction between feedback-seeking and performance history discussed below.) Job tenure demonstrated significant univariate main effects only on the performance/ potential measure $(F=9.09, p<.01)$; new workers were seen as having more ability and potential. No significant main effects were found for role.

There were no significant two-way multivariate interactions for tenure or role and feedback-seeking. These results disconfirm Hypotheses 1 and 2. In support of Hypothesis 3, there was a significant multivariate interaction between feedback-seeking and performance history $(F=4.97, p<$ .01) that was reflected in significant univariate interactions for both dependent measures $(F \mathrm{~s}>6.08, p \mathrm{~s}<.05)$. As shown in Table 5, feedbackseeking in general improved impressions of superior performers' personal characteristics and performance/potential, but did not help (and some- 
TABLE 4

Significance Tests of Independent Variable Effects on Personal Characteristics and Performance Potential

\begin{tabular}{|c|c|c|c|}
\hline & Multivariate $F$ & $\begin{array}{l}F \text {-personal } \\
\text { characteristics }\end{array}$ & $\begin{array}{c}F \text {-performance } \\
\text { potential }\end{array}$ \\
\hline \multicolumn{4}{|l|}{ Main effects } \\
\hline Feedback-seeking & $5.13^{* *}$ & 3.43 & $10.29 * * *$ \\
\hline Performance history & $151.48^{* * *}$ & $144.37^{* * *}$ & $295.48^{* * *}$ \\
\hline Job tenure & $6.81^{* *}$ & .01 & $9.09 * *$ \\
\hline Role & .54 & .89 & .56 \\
\hline \multicolumn{4}{|l|}{ Interactions } \\
\hline $\begin{array}{l}\mathrm{H}_{1} \text {-feedback-seeking by } \\
\text { tenure } \\
\mathrm{H}_{2} \text {-feedback-seeking by }\end{array}$ & .09 & .03 & .17 \\
\hline $\begin{array}{l}\text { role } \\
\mathrm{H}_{3} \text {-feedback-seeking by }\end{array}$ & 2.08 & 3.00 & 2.55 \\
\hline $\begin{array}{l}\text { performance history } \\
\text { Performance history }\end{array}$ & $4.97^{* *}$ & $6.08^{*}$ & $9.08^{* *}$ \\
\hline by tenure & 2.60 & .71 & 1.66 \\
\hline Performánce history & & & \\
\hline by role & .10 & .09 & .19 \\
\hline Tenure by role & $3.23^{*}$ & .09 & $5.04^{* *}$ \\
\hline Higher-order & & & \\
\hline interactions & $<2.64$ & $<2.50$ & $<1.0$ \\
\hline
\end{tabular}

what damaged) impressions of average performers. A significant multivariate interaction also was found for role and job tenure $(F=3.23, p<$ .05 ), reflected in a significant univariate interaction only for the performance potential measure $(F=5.04, p<.01)$; Supervisors received lower performance/potential ratings (6.78 compared to 6.87 for peers and 6.98 for subordinates), particularly if they were new to their jobs $(\bar{X}=6.69$ for new supervisors and 6.87 for longer-tenured supervisors). There were no other significant two-way or higher-order (three- or four-way) interactions.

In sum these results, which captured the viewpoint of an observer of the seeking act, directly contradicted the general proposition derived from Ashford and Cummings' (1983) theoretical work and supported by Study 1 , that feedback-seeking conveys a negative impression. The results also provide little support for Hypotheses 1 and 2: apparently being new or in a particular role are not relevant as discounting cues given the overall positive impression conveyed by feedback-seeking. Hypothesis 3 , however, was supported. Observers reacted differently to feedback- 
TABLE 5

Cell Means (Standard Deviations) for the

FeEdBaCk-SEEking-by-Performance-History INTERaCtion

\begin{tabular}{lccc}
\hline & $\begin{array}{c}\text { Did not seek } \\
\text { feedback }\end{array}$ & $\begin{array}{c}\text { Sought } \\
\text { feedback }\end{array}$ & Row mean \\
\hline $\begin{array}{l}\text { Personal characteristics } \\
\text { Performance history }\end{array}$ & 5.24 & & \\
$\quad$ Superior & $(1.13)$ & 5.71 & 5.50 \\
& 4.28 & $(.92)$ & $(1.04)$ \\
Only average & $(1.05)$ & 4.16 & 4.22 \\
& 4.71 & $(.76)$ & $(.91)$ \\
Column mean & $(1.19)$ & 4.90 & \\
& & $(1.14)$ & \\
Performance potential & 3.80 & & 4.01 \\
Performance history & $(.68)$ & & $(.61)$ \\
Superior & 2.96 & 4.18 & 2.94 \\
Only average & $(.56)$ & $(.50)$ & $(.55)$ \\
Column mean & 3.33 & 2.93 & \\
& $(.74)$ & $(.56)$ & \\
\hline
\end{tabular}

seeking when it was portrayed as coming from a superior performer versus an only average one.

\section{Discussion}

The results of Study 2 address three important issues and raise new questions regarding the impression management costs of feedbackseeking. First, does an individual's feedback-seeking behavior influence the impressions people form of that individual? The answer seems to be yes. In this study, subjects' assessments of the performance and advancement potential of a character in a vignette (Bob) differed depending on whether the character sought feedback or not. Apparently, feedbackseeking is a behavior observers use in forming impressions of others. Second, what kinds of impressions do people form of feedback-seekers? Feedback-seeking, when the character in the vignette was a superior performer, was associated with more favorable impressions (i.e., more favorable personal characteristics) and higher performance potential judgments. Feedback-seeking did not enhance the impressions of poor performers. As suggested by Hypothesis 3, the feedback-seeking act apparently is interpreted differently (in particular, more positively) when performed by a superior versus an average performer.

Finally, do the impression management costs of feedback-seeking found in Study 2 justify the impression-management concerns found in 
Study 1? Overall, feedback-seeking enhances observers' impressions of superior performers. When combined with the results of Study 1, these results suggest some actors-specifically superior performers-are not particularly accurate at predicting how their feedback-seeking will be construed by others. They act as if feedback-seeking conveys a negative message (i.e., they seek less when audiences are present) though observers may construe it positively. Thus, superior performers who attempt to protect their reputations by foregoing opportunities to seek feedback may be committing a "fundamental feedback error"-they think that seeking makes them look bad in the eyes of others when, in fact, it does not. These nonseeking superior performers pass up two valuable opportunities to enhance their organizational images. First, they do not receive the direct impression-enhancement effects of feedback-seeking. Second, if we believe the literatures' typical finding of a link between feedback and performance (cf. Kopelman, 1986) these nonseekers also pass up the benefits of improved performance through feedback.

This interaction between performance history and feedback-seeking was true whether the seeker was portrayed as the respondent's superior, subordinate, or peer. These results suggest that more theoretical and empirical guidance is needed regarding which sources individuals use (or should use) to obtain feedback and regarding the impressions that seekers in different roles convey. The current research suggests that if you are a superior performer, you ought to feel free to seek from your boss, your peers, or your subordinates equally. However, if performers operate on role congruency notions (i.e., if they believe that showing any uncertainty via seeking feedback is not consistent with the supervisor role) they might be particularly reluctant to seek from subordinates.

A note of caution should be sounded here in deference to the "richget-richer" interaction found between feedback-seeking and performance history. The methodology employed assesses only people's ideas about how they would evaluate a hypothetical feedback-seeker. This leaves the methodology open to two critiques. First, respondents may have been responding in a socially desirable manner, though the vignette gives few cues regarding the correct or appropriate response. Second, this methodology assesses respondents' beliefs about how they would respond to the feedback seeker. How they might actually respond is unknown (particularly if active feedback-seeking is currently a rare occurrence in the work settings) and will likely also depend on a variety of contextual variables beyond those measured here. However, Farr, Schwartz, Quinn, and Bittner (1989) also found positive effects of feedback-seeking on subjects taking the role of supervisors and observing the actual seeking of a "subordinate." Frequent feedback-seeking subordinates were judged to be more concerned and interested than were infrequent seekers. The simi- 
larity of these findings suggests that the limitations of the scenario methodology used here, while real, are not fatal.

As an early attempt to empirically document some of the consequences of feedback-seeking (rather than its antecedents), this research suggests that feedback-seeking offers impression-management benefits rather than costs for seekers, and the image-enhancement benefits of feedbackseeking are most available to superior performers. The picture is more complicated for lesser performers. In one sense they appear to be damned it they do and damned if they do not-perceived relatively more negatively if they seek feedback and having to work without it if they do not. However, this logic only recognizes the instrumental/informational value of feedback. Feedback, particularly the negative feedback that poor performers might obtain, also affects self-esteem and feelings of self-efficacy (cf. Podsakoff \& Fahr, 1989). Thus nonseeking poor performers may lose out in terms of not having the feedback they need to improve; such a strategy may be essential, however, for maintaining a necessary level of self-efficacy to allow some level of persistence at their tasks. Future research might profitably examine the boundary conditions of these effects. For example, does feedback-seeking convey as positive an impression the second time it occurs as it does the first? What about the fifth time or the tenth? Does the context affect impressions such that certain organizational realities may reduce the positive signal value of seeking while a high degree of environmental uncertainty (e.g., during an organizational transition) might enhance it? Finally, the availability and the clarity of task feedback might influence interpretations of the seeking act. If people seek feedback when both they and the observer can see that very clear task feedback is available, the seeking act may be seen as a sign of extreme weakness (if the task fecdback is negative) or ingratiation (e.g., inappropriately fishing for compliments) if the task feedback is positive.

From a practical standpoint, these findings add some urgency to the recommendations advanced in reaction to the findings of Study 1. Managers need to design work contexts that decrease the apparent impression-management costs of seeking feedback. Finding ways to enable feedback-seeking by poorer performers is especially important because studies have shown that individuals are often reluctant to give negative feedback (Tesser \& Rosen, 1975) and that poor performers often receive distorted feedback (Fisher, 1979; Ilgen \& Knowlton, 1980). Poor performers need to feel free to seek feedback, unencumbered by impressionmanagement concerns, lest their reluctance doom them to a downward spiral of less information, less performance, and a lesser organizational reputation. 


\section{APPENDIX \\ Sample Vignette ${ }^{1}$}

Today is a day like any other. You work for a large northeastern organization. You have several immediate co-workers, you report to a single superior, and you have s small staff reporting to you. You are sitting comfortably at your desk working on final preparations for your year-end area review when you hear a knock on your office door. You look up to find Bob, your immediate superior, standing in the doorway. Bob is new to his job, and has had a history of superior performance. You and $\overline{B o b}$ were involved in an important staff meeting yesterday. The meeting was long and covered a variety of topics. One of the topics of the meeting was a project that Bob is working on. Bob gave a prepared presentation that lasted about $15 \mathrm{~min}$, and then he spent about $5 \mathrm{~min}$ answering questions about the project. Bob asks if you are free for a few minutes. After the two of you exchange pleasantries, Bob asks you for some feedback about his presentation in the staff meeting you both attended yesterday.

\section{REFERENCES}

Argyle, M., \& Williams, M. (1969). Observer or observed? A reversible perspective in person perception. Sociometry, 32, 396-412.

Arkin, R. M. (1981). Self-presentation styles. In J. T. Tedeschi (Ed.), Impression Management Theory and Social Psychological Research (pp. 311-333). New York: Academic Press.

Ashford, S. J. (1986). The role of feedback seeking in individual adaptation: A resource perspective. Academy of Management Journal, 29, 465-487.

Ashford, S. J., \& Cummings, L. L. (1983). Feedback as an individual resource: Personal strategies of creating information. Organizational Behavior and Human Performance, 32, 370-398.

Blumberg, H. H. (1972). Communication of interpersonal evaluations. Journal of Personality and Social Psychology, 23, 157-162.

DeWhirst, H. D. (1971). Influence of perceived information sharing norms on communication channel utilization. Academy of Management Journal, 14, 303-315.

Eagly, A. H. (1967). Involvement as a determinant of response to favorable and unfavorable information. Journal of Personality and Social Psychology, 7, 1-15.

Eagly, A., \& Acksen, B. (1971). The effect of expecting to be evaluated on change toward favorable and unfavorable information about oneself. Sociometry, 34, 411-422.

Erez, M. (1977). Feedback: A necessary condition for the goal-setting performance relationship. Journal of Applied Psychology, 64, 533-540.

Farr, J. L., Schwartz, A. C., Quinn, J. C., \& Bittner, K. L. (1989, April). Consequences of feedback seeking on supervisory performance ratings and attributions. Paper presented at the Fourth Annual Conference, Society for Industrial and Organizational Psychology, Boston, MA.

${ }^{1}$ The relevant phrases representing the variables are underlined here for ease of exposition. They were not underlined when used in the study. 
Fedor, D. B., Eder, R. W., \& Buckley, M. R. (1989). The contributory effects of supervisor intentions on subordinate feedback responses. Organizational Behavior and Human Decision Processes, 44, 396-414.

Feldman, D. C., \& Brett, J. M. (1983). Coping with new jobs: A comparative study of new hires and job changers. Academy of Management Journal, 26, 258-272.

Fenigstein, A. (1979). Self-consciousness, self-attention and social interaction. Journal of Personality and Social Psychology, 37, 75-86.

Fenigstein, A., Scheier, M. F., \& Buss, A. H. (1975). Public and private self-consciousness assessment and theory. Journal of Consulting and Clinical Psychology, 43, 522-527.

Ferris, R., \& Porac, J. (1984). Goal setting as impression management. Journal of Psychology, 117, 33-36.

Festinger, L. (1954). A theory of social comparison processes. Human Relations, 7, 117140 .

Fisher, C. D. (1979). Transmission of positive and negative feedback to subordinates: A laboratory investigation. Journal of Applied Psychology, 64, 533-540.

Ilgen, D. R., Fisher, C. D., \& Taylor, S. M. (1979). Consequences of individual feedback on behavior in organizations. Journal of Applied Psychology, 64, 359-371.

Ilgen, D. R., \& Knowlton, W. A. (1980). Performance attributional effects on feedback from subordinates. Organizational Behavior and Human Performance, 25, 441-456.

Jones, E. E., Davis, D. E., \& Gergen, K. J. (1961). Role playing variations and their information value for person perception. Journal of Abnormal and Social Psychology, 63, 302-310.

Katz, S., \& Burnstein, E. (1975). Is an out-of-role act credible to biased observers and does it affect the credibility of neutral acts? Journal of Personality, 43, 215-230.

Kelley, H. H. (1973). The processes of causal attribution. American Psychologist, 28, 107128.

Kelley, H. H. (1967). Attribution theory in social psychology. In D. Levine (Ed.), Nebraska Symposium on Motivation. Lincoln: University of Nebraska Press.

Kopelman, R. (1986). Objective feedback. In E. A. Locke (Ed.), Generalizing from the Laboratory to Field Settings. Lexington, MA: Lexington Books.

Larson, J. R., Jr. (1984). The performance feedback process: A preliminary model. Organizational Behavior and Human Performance, 33, 42--76.

Northcraft, G. B., \& Ashford, S. J. (1990). The preservation of self in everyday life: The effects of performance expectations and feedback context on feedback inquiry. Organizational Behavior and Human Decision Processes, 47, 42-64.

Podsakoff, P. M., \& Farh, J. (1989). Effects of feedback sign and credibility on goal setting and task performance. Organizational Behavior and Human Decision Processes, 44, $45-67$,

Sandelands, L. E., \& Calder, B J. (1987). Perceptual organization in task performance. Organizational Behavior and Human Decision Processes, 40, 287-306.

Schneider, D. (1981). Tactical self-presentations: Toward a broader conception. In J. T. Tedeschi (Ed.), Impression Management Theory and Social Psychological Research (pp. 23-40). New York: Academic Press.

Schneider, D. (1969). Tactical self-presentation after success and failure. Journal of Personality and Social Psychology, 13, 262-268.

Schoeneman, T. J. (1981). Reports of sources of self knowledge. Journal of Personality, 49, $289-293$.

Staw, B. M. (1975). Attribution of the "causes" of performance: A general alternative interpretation of cross-sectional research on organizations. Organizational Behavior and Human Performance, 13, 414-432.

Staw, B. M., \& Ross, J. (1987). Behavior in escalation situations: Antecedents, prototypes 
and solutions. In L. L. Cummings \& B. M. Staw (Eds.), Research in Organizational Behavior (Vol. 9, pp. 39-78). Greenwich, CT: JAI Press.

Tesser, A., \& Rosen, S. (1975). The reluctance to transmit bad news. In L. Berkowitz (Ed.), Advances in Experimental Social Psychology. New York: Academic Press.

Tetlock, P. E., \& Manstead, A. S. R. (1985). Impression management versus intrapsychic explanations in social psychology: A useful dichotomy. Psychological Review, 92, 5977.

Turner, R. G., Carver, C. S., Scheier, M. F., \& Ickes, W. (1978). Correlates of self consciousness. Journal of Personality Assessment, 42(3), 285-289.

Vroom, V. H. (1964). Work and Motivation. New York: Wiley.

Winer, B. J. (1971). Statistical Principles in Experimental Design. New York: McGrawHill.

Wolfe, E. (1989). Feedback Seeking Behavior and the Presentation of Self. Paper presented at the National Academy of Management Meetings, Washington, DC.

Wood, R., \& Mitchell, T. (1981). Manager behavior in a social context: The impact of impression management on attributions and disciplinary actions. Organizational Behavior and Human Performance, 28, 356-378.

RECEIVED: November 30, 1989 